\title{
Development of an automated system for isolation and purification of humic substances
}

\author{
A. van Zomeren \\ E. van der Weij-Zuiver \\ R.N.J. Comans
}

Published in Anal Bioanal Chem (2008) 391:2365-2370 


\title{
Development of an automated system for isolation and purification of humic substances
}

\author{
André van Zomeren • Esther van der Weij-Zuiver • \\ Rob N. J. Comans
}

Received: 12 February 2008 /Revised: 24 April 2008 /Accepted: 25 April 2008 / Published online: 17 May 2008

(C) Springer-Verlag 2008

\begin{abstract}
Characterization of humic substances (HS) in environmental samples generally involves labor-intensive and time-consuming isolation and purification procedures. In this paper, the development of an automated system for HS isolation and purification is described. The novelty of the developed system lies in the way the multiple liquids and columns used in the isolation/purification procedure are handled in both forward and back-elution mode by solenoid valves. The automated procedure significantly reduces the total throughput time needed, from 6-7 days to $48 \mathrm{~h}$, and the amount of labor to obtain purified HS for further characterization. Chemical characterization of purified HS showed that results were in good agreement with previously published values for HS from a variety of sources, including the IHSS standard HS collection. It was also shown that the general properties of HS were consistent among the different source materials (soil, waste, aquatic) used in this study. The developed system greatly facilitates isolation and characterization of HS and reduces the risk of potential
\end{abstract}

Electronic supplementary material The online version of this article (doi:10.1007/s00216-008-2163-0) contains supplementary material, which is available to authorized users.

A. van Zomeren · E. van der Weij-Zuiver • R. N. J. Comans $(\bowtie)$ Energy Research Centre of The Netherlands (ECN),

Post Office Box 1, 1755 ZG Petten, The Netherlands

e-mail: comans@ecn.nl

R. N. J. Comans

Department of Soil Quality, Wageningen University,

P.O. Box 47, 6700 AA Wageningen, The Netherlands

Present address:

E. van der Weij-Zuiver

Chefaro Nederland BV,

P.O. Box 6014, 3002 AA Rotterdam, The Netherlands (time-dependent) alteration of HS properties in the manual procedure.

Keywords Natural organic matter · Humic acid .

Fulvic acid $\cdot$ Isolation $\cdot$ Purification $\cdot$ IHSS method

\section{Introduction}

Natural organic matter (NOM) in the environment can be of plant, animal, or microbial origin and may range from relatively fresh to highly decomposed and transformed. NOM plays an important role in, for example, soil properties such as cation-exchange capacity, soil structure, water entry and retention, nutrient cycling, and binding of heavy metals and organic micropollutants [1,2]. The study of these properties often requires isolation and purification of organic matter.

Currently, the International Humic Substances Society (IHSS) uses the adapted fractionation method of Aiken [3], earlier described in detail by Thurman and Malcolm [4], for isolation and purification of humic (HA) and fulvic acid (FA) standards from aqueous samples, and the method of Swift [2] for solid source materials. These methods are based on precipitation of $\mathrm{HA}$ at $\mathrm{pH} 1$ or 2 and adsorption of HA and/or FA on the macroporous XAD-8 resin. Adsorbed HS are subsequently desorbed with $0.1 \mathrm{~mol} \mathrm{~L}^{-1} \mathrm{NaOH}$ and cations are removed by a cation-exchange resin. The reader is referred to Refs. [2-5] for detailed descriptions of the methods of isolation. Although these procedures are well established and widely used by scientists, they all share the disadvantage of being very laborious, particularly because of the manual handling of the multiple liquids and columns that are required. 
This paper describes the development of an automated system to perform isolation and purification of HS, especially from solid source materials. The setup of the system is very flexible and easy to modify, which allows methods that involve HA separation after prior preconcentration and purification (e.g. Thurman and Malcolm [4] and Leenheer [5]). However, these methods then involve intermediate HA separation by acidification and centrifugation. The novelty of the method lies in the automated handling of the multiple liquids and columns, required in the isolation/purification procedure, in both forward and back-elution mode. The particular experimental set up allows the procedure to be executed with only a single pump and flowmeter. Our main objective for automation of the IHSS procedure was to save a significant amount of labor and total throughput time in the performance of HS isolation and purification. By automating the procedure, our objective is also better standardization of the HS isolation and purification methods.

\section{Materials and methods}

\section{Reagents}

All reagents used were of analytical-grade quality. Double demineralized water (nanopure) was used for preparation of reagents. Every new batch of XAD-8 (Amberlite) was first cleaned to remove organic impurities by five consecutive 24-h extractions with $0.1 \mathrm{~mol} \mathrm{~L}^{-1} \mathrm{HCl}$ and $0.1 \mathrm{~mol} \mathrm{~L}^{-1} \mathrm{NaOH}$. Fine floating particles were removed by decantation. The XAD- 8 and the cation-exchange resin (Biorad AG-MP-50, 100-200 mesh) resin were thoroughly cleaned by Soxhlet extraction with acetonitrile and methanol, each for $24 \mathrm{~h}$. The cleaned resins were stored in methanol until use.

\section{Samples}

The automated procedure was performed (according to Swift [2]) on a peat (Devoke UK), a compost sample, a landfill waste mixture, and a sample of municipal solid waste incineration (MSWI) bottom ash. Moreover, HS from four aquatic samples, a landfill leachate, influent and effluent water from a landfill water treatment plant, and water from a DOC-rich pond in a nature reserve (Zwanenwater, NL), were isolated and purified according to Thurman and Malcolm [4]. All purified HS (except from MSWI bottom ash) were also characterized by the method of van Zomeren and Comans [6].

\section{Hardware}

The experimental setup of the procedure is outlined in Fig. 1. The lines in the scheme represent Teflon tubing (FEP, 1/8" O.D., 1/16" I.D.) connected to several two-way
Fig. 1 Schematic representation of the automated isolation and purification system. An asterisk marks the manual option (Omnifit manual three-way connector, part: 1102) to de-aerate the tubing and the pump before each experiment. Dashed lines mark connections from fractions that are first produced (F2 and F4) in the procedure and that are later used in subsequent elution steps (FA1 + FA2 and FA3). $\mathrm{N}_{2}$ gas was supplied to the eluate FA3 (fraction 4) until it was purified by the cation-exchange resin. Sample vessels F2 (containing $6 \mathrm{~mol} \mathrm{~L}^{-1} \mathrm{HCl}$ and concentrated $\mathrm{HF}$ ) and F4 were placed on a magnetic stirrer with a Tefloncoated magnet to homogenize the solution

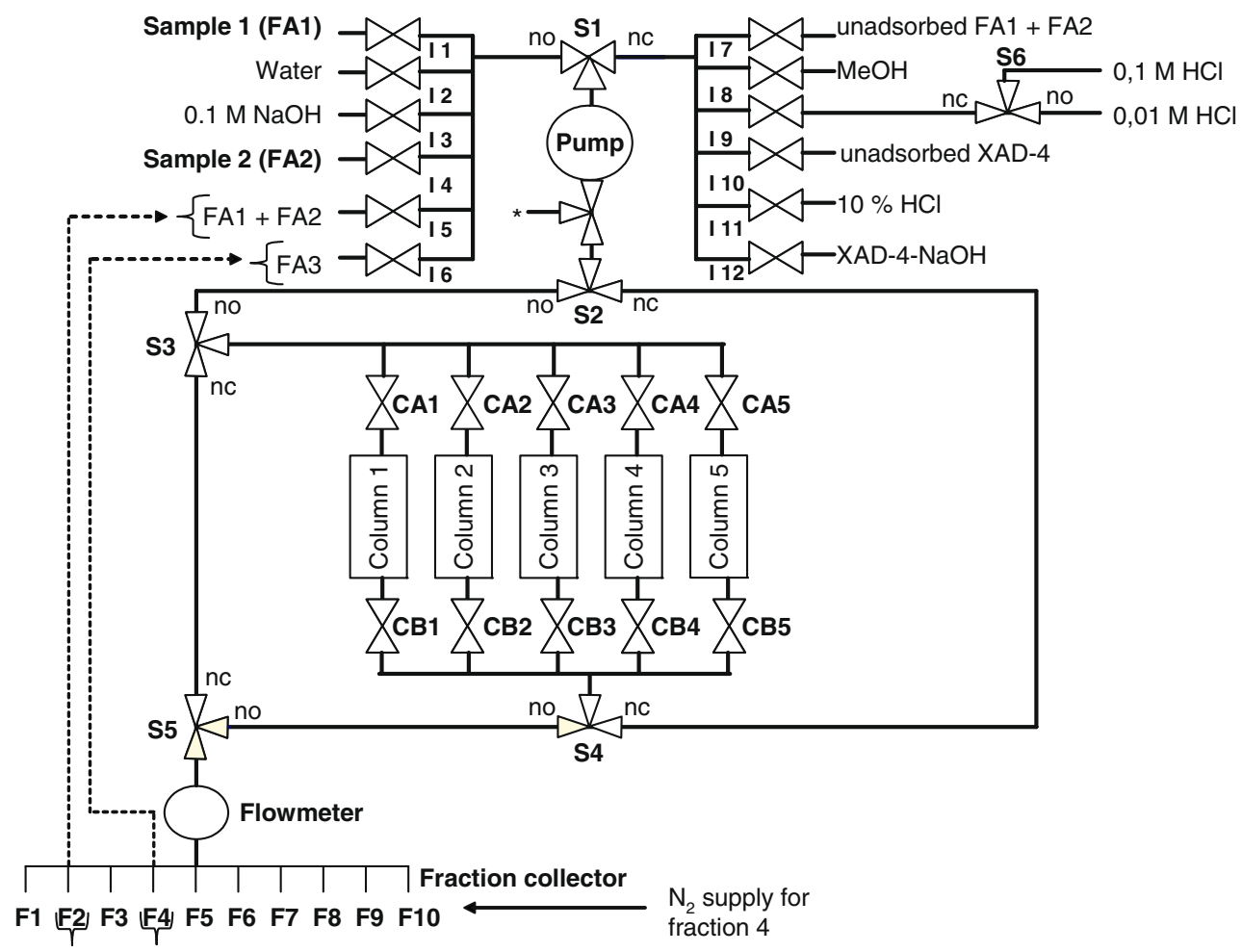


Table 1 Procedure statements used to perform the isolation and purification procedure of Swift [2]

\begin{tabular}{|c|c|c|c|c|c|c|}
\hline Step & Description & Stop volume & Column & Fraction & Flow & Deviation \\
\hline 1 & Pumping water through column 4 (i2) & $20 \times \operatorname{cv} 4$ & 4 & 3 & $\mathrm{fl} 4$ & 5 \\
\hline 2 & Pumping $10 \% \mathrm{HCl}$ through column 4 (i11) & $15 \times \mathrm{cv} 4$ & 4 & 3 & $0.6 \times \mathrm{fl} 4$ & 5 \\
\hline 3 & Pumping water through column 1 (i2) & $20 \times \mathrm{cv} 1$ & 1 & 3 & fl1 & 5 \\
\hline 4 & Pumping water through column 2 (i2) & $20 \times$ cv2 & 2 & 3 & $\mathrm{fl} 2$ & 5 \\
\hline 5 & Pumping water through column 3 (i2) & $20 \times \operatorname{cv} 3$ & 3 & 3 & $\mathrm{fl} 3$ & 5 \\
\hline 6 & Pumping $0.01 \mathrm{~mol} \mathrm{~L}^{-1} \mathrm{HCl}$ through column 1 (i8) & $1.5 \times \mathrm{cv} 1$ & 1 & 3 & $\mathrm{fl1}$ & 5 \\
\hline 7 & Pumping FA1 through column 1 (i1) & $0.95 \times$ FA 1 & 1 & 1 & fl1 & 5 \\
\hline 8 & Pumping 0.65 column volumes of water through column 1 (i2) & $0.65 \times \mathrm{cv} 1$ & 1 & 1 & fl1 & 5 \\
\hline 9 & Back-eluting with 1.5 column volume of $0.1 \mathrm{~mol} \mathrm{~L}^{-1} \mathrm{NaOH}$ (i3) & $1.5 \times \mathrm{cv} 1$ & 1 & 2 & fl1 & 5 \\
\hline 10 & Back-eluting with 3.5 column volumes of water (i2) & $3.5 \times \mathrm{cv} 1$ & 1 & 2 & fl1 & 5 \\
\hline 11 & Pumping $0.01 \mathrm{~mol} \mathrm{~L}^{-1} \mathrm{HCl}$ through column 2 (i8) & $1.5 \times \mathrm{cv} 2$ & 2 & 3 & $\mathrm{fl} 2$ & 5 \\
\hline 12 & Pumping FA2 through column 2 (i4) & $0.98 \times \mathrm{FA} 2$ & 2 & 6 & $\mathrm{fl} 2$ & 5 \\
\hline 13 & Pumping 0.65 column volumes of water through column 2 (i2) & $0.65 \times \mathrm{cv} 2$ & 2 & 6 & $\mathrm{f} 12$ & 5 \\
\hline 14 & Back-eluting with 1.5 column volumes $0.1 \mathrm{~mol} \mathrm{~L}^{-1} \mathrm{NaOH}$ (i3) & $1.5 \times \mathrm{cv} 2$ & 2 & 2 & $\mathrm{fl} 2$ & 5 \\
\hline 15 & Back-eluting with 3.5 column volumes of water (i2) & $3.5 \times \mathrm{cv} 2$ & 2 & 2 & $\mathrm{fl} 2$ & 5 \\
\hline 16 & Pumping $0.01 \mathrm{~mol} \mathrm{~L}^{-1} \mathrm{HCl}$ through column 3 (i8) & $1.5 \times \operatorname{cv} 3$ & 3 & 3 & $\mathrm{fl} 3$ & 5 \\
\hline 17 & Pumping FA1+FA2 through column 3 (i5) & $4.9 \times(\mathrm{cv} 1+\mathrm{cv} 2)$ & 3 & 1 & $\mathrm{fl} 3$ & 5 \\
\hline 18 & Pumping 0.65 column volumes of water through column 3 (i2) & $0.65 \times \mathrm{cv} 3$ & 3 & 1 & $\mathrm{fl} 3$ & 5 \\
\hline 19 & Back-eluting with 1.5 column volumes $0.1 \mathrm{~mol} \mathrm{~L}^{-1} \mathrm{NaOH}$ (i3) & $1.5 \times \mathrm{cv} 3$ & 3 & 4 & $\mathrm{fl} 3$ & 5 \\
\hline 20 & Back-eluting with 3.5 column volumes of water (i2) & $3.5 \times \mathrm{cv} 3$ & 3 & 4 & $\mathrm{fl} 3$ & 5 \\
\hline 21 & Pumping water through column 4 (i2) & $20 \times \operatorname{cv} 4$ & 4 & 3 & $\mathrm{fl} 4$ & 5 \\
\hline 22 & Pumping FA3 through column 4 (i6) & $4.9 \times(\mathrm{cv} 3)$ & 4 & 5 & $\mathrm{fl} 4$ & 5 \\
\hline 23 & Pumping 2 column volumes of water through column 4 (i2) & $2 \times \mathrm{cv} 4$ & 4 & 5 & $\mathrm{fl} 4$ & 5 \\
\hline
\end{tabular}

The steps are executed in increasing number until the stop volume is reached. Sample (FA1/FA2) and column volumes $(\mathrm{CV}<\mathrm{n}>)$ are entered by the user in the user interface and the flow $\left(\mathrm{FL}<\mathrm{n}>\right.$ ) is derived from these volumes (default: $5 \mathrm{CV} \mathrm{h}^{-1}$ ). Column number, fraction number, and the deviation in the stop volume (\%) are given for each step

(Takasago, type, $24 \mathrm{~V} \mathrm{DC}$ ) and three-way solenoid valves (Furon, model 1101493, 24 V DC) by Omnifit PEEK fitting nuts (part 2222) and grippers (part 2312). All valves and fraction-collector positions of the system were named and used in the database (see "Software" section) to specify their function (Tables 1 and 2). The position of the fraction collector is denoted F1-10 (Fraction). The two-way valves that control the liquid to be pumped are named I1-

Table 2 Modbus addresses and status of the solenoid valves in each step of the isolation and purification procedure according to Swift [2]

\begin{tabular}{|c|c|c|c|c|c|c|c|c|c|c|c|c|c|c|c|c|c|c|c|c|c|c|c|c|c|c|c|c|}
\hline \begin{tabular}{|l|} 
Modbus \\
Address \\
\end{tabular} & 22 & 23 & 24 & 25 & 26 & 27 & 0 & 1 & 2 & 3 & 4 & 5 & 6 & 7 & 8 & 9 & 10 & 11 & 12 & 13 & 14 & 15 & 16 & 17 & 18 & 19 & 20 & 21 \\
\hline Step/Valve & S1 & $\mathrm{S} 2$ & S3 & S4 & S5 & S6 & 11 & 12 & 13 & 14 & 15 & 16 & 17 & 18 & 19 & 110 & 111 & $\mid 12$ & CA1 & CA2 & CA3 & CA4 & CA5 & CB1 & CB2 & CB3 & CB4 & CB5 \\
\hline 1 & & & & & & & & & & & & & & & & & & & & & & & & & & & & \\
\hline 2 & & & & & & & & & & & & & & & & & & & & & & & & & & & & \\
\hline 3 & & & & & & & & & & & & & & & & & & & & & & & & & & & & \\
\hline 4 & & & & & & & & & & & & & & & & & & & & & & & & & & & & \\
\hline 5 & & & & & & & & & & & & & & & & & & & & & & & & & & & & \\
\hline 6 & & & & & & & & & & & & & & & & & & & & & & & & & & & & \\
\hline 7 & & & & & & & & & & & & & & & & & & & & & & & & & & & & \\
\hline 8 & & & & & & & & & & & & & & & & & & & & & & & & & & & & \\
\hline 9 & & & & & & & & & & & & & & & & & & & & & & & & & & & & \\
\hline 10 & & & & & & & & & & & & & & & & & & & & & & & & & & & & \\
\hline 11 & & & & & & & & & & & & & & & & & & & & & & & & & & & & \\
\hline 12 & & & & & & & & & & & & & & & & & & & & & & & & & & & & \\
\hline 13 & & & & & & & & & & & & & & & & & & & & & & & & & & & & \\
\hline 14 & & & & & & & & & & & & & & & & & & & & & & & & & & & & \\
\hline 15 & & & & & & & & & & & & & & & & & & & & & & & & & & & & \\
\hline 16 & & & & & & & & & & & & & & & & & & & & & & & & & & & & \\
\hline 17 & & & & & & & & & & & & & & & & & & & & & & & & & & & & \\
\hline 18 & & & & & & & & & & & & & & & & & & & & & & & & & & & & \\
\hline 19 & & & & & & & & & & & & & & & & & & & & & & & & & & & & \\
\hline 20 & & & & & & & & & & & & & & & & & & & & & & & & & & & & \\
\hline 21 & & & & & & & & & & & & & & & & & & & & & & & & & & & & \\
\hline 22 & & & & & & & & & & & & & & & & & & & & & & & & & & & & \\
\hline 23 & & & & & & & & & & & & & & & & & & & & & & & & & & & & \\
\hline
\end{tabular}

The grey cells indicate that the appropriate valve is opened during the specific step in the procedure 
12 (input). The system contains two blocks (Takasago, MTV-2-6NMFG-1, $24 \mathrm{~V}$ DC) with six solenoid valves (manifolds). Additionally, two manifolds (Takasago, MTV2 -5NMFG-1, 24 V DC) with five valves above and below the columns are named CA1-5 and CB1-5 (Column), respectively. The system was developed to perform the isolation and purification procedures of Swift [2], Thurman and Malcolm [4], and Leenheer [5]. Therefore, the connections and liquids for all of these methods are addressed in Fig. 1 (e.g. liquid inputs I8, I9, and I12).

The six three-way valves (S1-6, Switch) were used to reverse the flow to perform back elution during recovery of the purified HS. The normally open (no) and normally closed (nc) positions of the valves are noted in Fig. 1. Glass columns (Omnifit $2.5 \mathrm{~cm}$ I.D. $\times 40 \mathrm{~cm}$ for XAD-8 and Omnifit $1.5 \mathrm{~cm}$ I.D. $\times 40 \mathrm{~cm}$ for AG-MP-50) were used and the adjustable endpieces (2008NS and 6465NS) were equipped with $100 \mu \mathrm{m}$ PTFE frits (6243NS).

All liquids were pumped (ProMinent Verder; Type: GALA1602TTT000UA002000) after the appropriate set of valves was opened (Tables 1 and 2). To reduce pressure pulses from the pump, either silicone tubing $(0.7 \mathrm{~mm}$ I.D., $1 \mathrm{~mm}$ O.D.) or special crimped flexible PTFE tubing ( $3 \mathrm{~mm}$ I.D., $5.5 \mathrm{~mm}$ O.D., Polyfluor, NL) can be installed behind the pump. The flow was measured with a liquid flowmeter (G.J.C. Instruments, model 5025500) and adjusted to the set point value by the software. A home-made rotating fraction collector collected the eluates in the various bottles using a stepper motor (Astrosyn, Y129, art. 586389, $12 \mathrm{~V}$ DC, $0.16 \mathrm{~A}$ ). The home position (fraction number 1) was determined with an inductive sensor (Balluff, BES 5163005-E4-C-PU-05).

\section{Communications}

The data I/O system contains several modules (Wago) for control of the valves, pump, inductive sensor, and stepper motor. All modules and their functions are specified in Table S1, the connections are shown in Figure S1 (Electronic Supplementary Material). The I/O modules were connected to the fieldbus network system (Modbus/ RS232 communication) by a fieldbus controller (750-814), which was connected to COM1 of the PC. The second serial port of the PC (COM2) was used to communicate with the liquid flowmeter (RS232).

\section{Software}

The software was developed to control the pump, valves, flow meter, and fraction collector and includes a user interface to specify experiments. During the experiment the current status of each step is displayed and the user is allowed to stop or pause the experiment. Liquid volumes, elapsed time, flow, and experiment set points are written to a data file. A Flow diagram showing the sequence of events during execution of a typical experiment is shown in Fig. 2. The software can be obtained from the authors free of charge.

The experimental configuration, procedure definitions (Table 1) and Modbus protocol register addresses (Table 2) were stored in a MS Access database.

\section{Elemental analysis of purified HS}

The elemental composition (CHNO) of the purified HS (after drying at $110^{\circ} \mathrm{C}$ ) was analyzed with a Carlo Erba

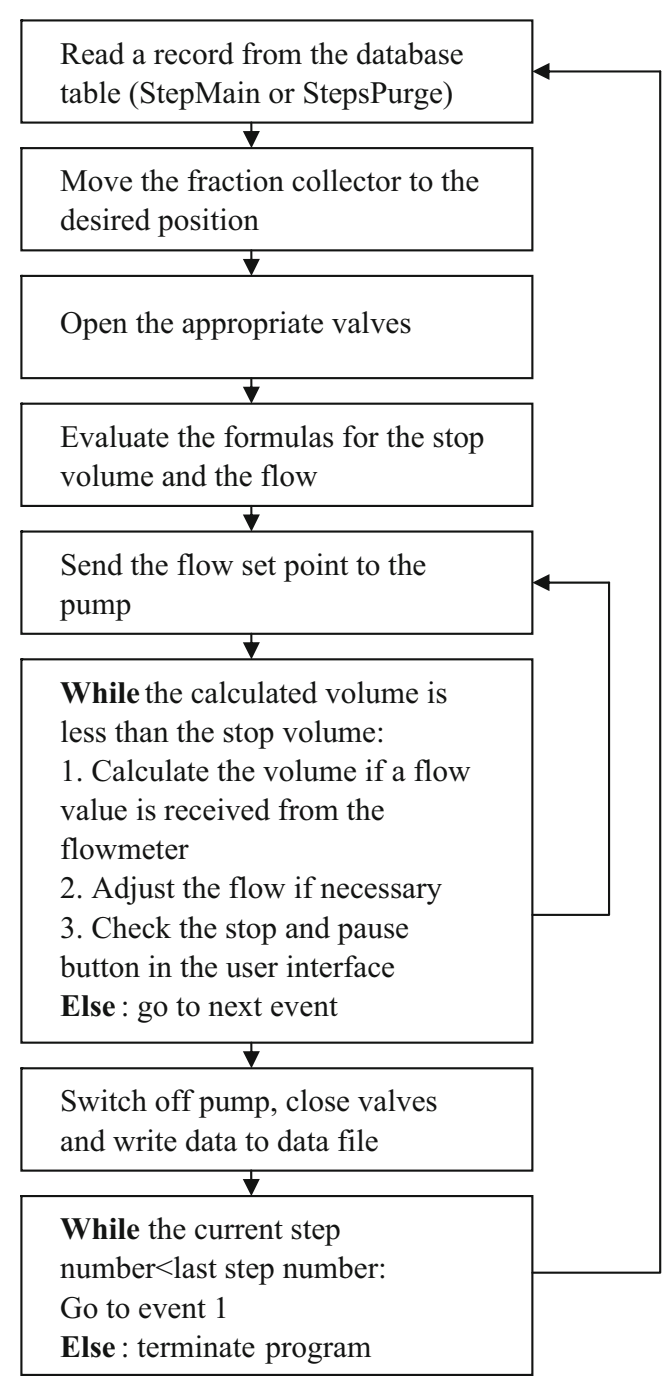

Fig. 2 Flow diagram showing the sequence of events during the execution of a typical experiment. The data used in the sequence are read from Table 1 . The flow is adjusted by addition or subtraction of the offset in the flow (set point flow-actual flow). The experiment can be stopped or paused in the user interface at any time during the experiment 
Table 3 Chemical composition (based on dry matter and ash free basis) in \% (w/w) and UV-visible characteristics of isolated and purified HA and FA from various sources

\begin{tabular}{|c|c|c|c|c|c|c|c|c|c|c|c|c|c|}
\hline Sample & $\begin{array}{l}\mathcal{\varepsilon}\left(\mathrm{L}(\text { mole } \mathrm{C})^{-1}\right. \\
\left.\mathrm{cm}^{-1}\right)^{\mathrm{a}}\end{array}$ & $\begin{array}{l}\text { Aromaticity }{ }^{\mathrm{b}} \\
(\%)\end{array}$ & $\begin{array}{l}\text { E4/ } \\
\text { E6 }\end{array}$ & $\begin{array}{l}\mathrm{C} \\
(\%)\end{array}$ & $\begin{array}{l}\mathrm{O} \\
(\%)\end{array}$ & $\begin{array}{l}\mathrm{H} \\
(\%)\end{array}$ & $\begin{array}{l}\mathrm{N} \\
(\%)\end{array}$ & $\begin{array}{l}\mathrm{S} \\
(\%)\end{array}$ & $\begin{array}{l}\text { Sum } \\
\text { CHNOS }\end{array}$ & $\begin{array}{l}\mathrm{H}_{2} \mathrm{O} \\
(\%)\end{array}$ & $\begin{array}{l}\text { Ash } \\
(\%)\end{array}$ & $\begin{array}{l}\mathrm{O} / \\
\mathrm{C}^{\mathrm{c}}\end{array}$ & $\begin{array}{l}\mathrm{H} / \\
\mathrm{C}^{\mathrm{c}}\end{array}$ \\
\hline Compost HA & 532.2 & 33.3 & 6.9 & 56.0 & 30.9 & 5.1 & 7.5 & $<0.5$ & 99.5 & 8.5 & 7.4 & 0.41 & 1.10 \\
\hline Compost FA & 31.6 & 8.3 & $\mathrm{Na}$ & 53.8 & 34.8 & 5.1 & 5.0 & $<0.5$ & 98.6 & 5.5 & 11.7 & 0.49 & 1.14 \\
\hline Peat HA & 390.8 & 26.3 & 5.2 & 55.3 & 34.8 & 5.9 & 3.8 & $<0.1$ & 99.8 & 6.8 & 4.5 & 0.47 & 1.27 \\
\hline Peat FA & 381.1 & 25.8 & $16.0^{\mathrm{d}}$ & 52.9 & 39.6 & 4.8 & 1.5 & $<0.1$ & 98.9 & 9.0 & 10.3 & 0.56 & 1.10 \\
\hline $\begin{array}{l}\text { Landfill waste } \\
\text { HA }\end{array}$ & 426.5 & 28.1 & $16.0^{\mathrm{d}}$ & 56.2 & 30.7 & 6.0 & 5.5 & 1.5 & 99.9 & 4.4 & 2.4 & 0.41 & 1.28 \\
\hline $\begin{array}{l}\text { Landfill waste } \\
\text { FA }\end{array}$ & 285.5 & 21.0 & 6.3 & 54.6 & 35.5 & 5.3 & 2.2 & 1.8 & 99.3 & 8.5 & 7.7 & 0.49 & 1.16 \\
\hline $\begin{array}{l}\text { MSWI bottom } \\
\text { ash HA }\end{array}$ & na & na & na & 64.4 & 21.6 & 7.0 & 6.2 & na & 99.3 & 8.9 & 8.3 & 0.25 & 1.31 \\
\hline $\begin{array}{l}\text { MSWI bottom } \\
\text { ash FA }\end{array}$ & na & na & na & 53.3 & 38.3 & 5.3 & 3.1 & na & 99.9 & 8.5 & 3.1 & 0.54 & 1.18 \\
\hline Effluent HA & 348.4 & 24.2 & $17.3^{\mathrm{d}}$ & 56.4 & 31.2 & 5.5 & 5.4 & na & 98.5 & 9.9 & 12.2 & 0.41 & 1.17 \\
\hline Effluent FA & 255.6 & 19.5 & na & 55.7 & 34.6 & 5.8 & 2.0 & 1.5 & 99.5 & 5.8 & 6.0 & 0.47 & 1.24 \\
\hline Influent HA & 272.7 & 20.4 & 9.5 & 58.9 & 28.4 & 6.0 & 3.7 & 2.3 & 99.4 & 5.8 & 6.7 & 0.36 & 1.23 \\
\hline Influent FA & 168.8 & 15.2 & na & 59.6 & 30.4 & 6.5 & 1.4 & 1.7 & 99.6 & 6.5 & 5.3 & 0.38 & 1.31 \\
\hline Leachate HA & 318.3 & 22.7 & 6.3 & na & na & na & na & na & na & na & na & na & na \\
\hline Leachate FA & 151.1 & 14.3 & na & 57.6 & 32.1 & 6.3 & 0.9 & 2.7 & 99.6 & 7.2 & 5.1 & 0.42 & 1.31 \\
\hline $\begin{array}{l}\text { Zwanenwater } \\
\text { HA }\end{array}$ & na & na & na & 53.5 & 37.7 & 4.5 & 2.7 & 1.5 & 99.9 & 7.9 & 3.0 & 0.53 & 1.01 \\
\hline $\begin{array}{l}\text { Zwanenwater } \\
\text { FA }\end{array}$ & na & na & na & 52.7 & 40.0 & 4.3 & 1.5 & 1.4 & 99.8 & 7.9 & 3.4 & 0.57 & 0.98 \\
\hline
\end{tabular}

${ }^{\text {a }}$ Measured at $280 \mathrm{~nm}$, based on the molar mass of carbon

${ }^{\mathrm{b}}$ Based on UV absorption at $280 \mathrm{~nm}$, according to Ref. [10]

${ }^{\mathrm{c}}$ Atomic ratio

${ }^{\mathrm{d}}$ Relatively high ratio because of very low absorption at $665 \mathrm{~nm}$

Flash EA 1112 element analyzer. Elemental S was determined by ICP-AES after digestion in $\mathrm{HNO}_{3} / \mathrm{HClO}_{4}$. The water content of the HS was determined separately on "as stored" samples by a Karl Fischer titration. The ash content was determined by subtraction of the total $\mathrm{C}, \mathrm{H}, \mathrm{N}$, $\mathrm{O}$, and $\mathrm{S}$ content from $100 \%$.

\section{Results and discussion}

Performance characteristics of the automated procedure

The total throughput time of the automated system is about $48 \mathrm{~h}$ when a sample is isolated according to Swift [2]. Since the automated procedure also continues during the night, the purification process is finished after two working days. It is obvious that a significant additional amount of time is saved on checking/adjusting the experimental progress. It is noted that time saving only occurs in the column operation procedure itself, since the several sample extractions (acid and base) before the column procedure and the subsequent freeze drying of the obtained FA product are identical to the manual procedure.
Without the intention of specific comparison with the manual procedure, we tested the accuracy of the purified FA amounts in a duplicate isolation experiment with the compost sample. It was found that the differences were within 5\% (3701 and $3586 \mathrm{mg} \mathrm{FA} \mathrm{kg}^{-1}$ ), suggesting an excellent experimental performance.

Results of the automated procedure are in good agreement with those obtained by use of a recently developed rapid batch procedure for quantification of HS [6]. The recovery of HA and FA was found to depend on the extraction conditions, in particular $\mathrm{pH}$, HS concentration, and resin loading. Because these conditions do not differ between the manual and automated procedure, the HS recovery of both procedures will be identical.

Moreover, automation of the isolation procedure also overcomes practical problems in the planning of the experimental work. When the IHSS method [2] is performed manually, the total throughput time is about 6 7 days. Therefore, it is almost inevitable that the semipurified HS are subjected to prolonged standing in acid or base. It has been found that FA storage in acidic solutions may induce polymerization, whereas storage in alkaline solutions can also lead to significant alteration of the 
organic matter characteristics [7]. In addition, adsorbed HS might remain on the XAD-8 resin overnight before being desorbed. This is also unwanted because of resin bleeding $[8,9]$, that will be higher for increasing contact times. Therefore, we suggest that the original properties of FA are better retained by the new automated system.

\section{Practical considerations}

Before the experiment, air is manually removed from the tubing with a syringe (at point $*$ in Fig. 1 ) and by bypassing the columns with a manually operated three-way valve. When running experiments at flow rates above about $10 \mathrm{~mL} \min ^{-1}$, degassing the demineralized water in an ultrasonic water bath is recommended.

The first purified alkaline FA extract (steps 9, 10, 14 and 15 in Table 1) is immediately acidified with $6 \mathrm{~mol} \mathrm{~L}^{-1} \mathrm{HCl}$ (added manually to bottle F2 before start of the procedure) to prevent possible auto-oxidation of the alkaline FA extract. Concentrated HF can be used to reduce the ash content of the FA, yet there is still debate about its effects on the properties of purified FA [7]. To prevent possible damage of the flowmeter (which contains a glass measuring tube), concentrated HF is added by use of a home made semi-floating vessel which is designed such that the HF is added after about half of the total eluted volume has entered the collection bottle.

\section{Chemical characterization of purified HS}

Relevant properties of the samples that have been isolated and purified with the new automated procedure are summarized in Table 3. These results are generally in good agreement with other published values for HS from a variety of sources, including standard HS from the IHSS [10-12]. Given the heterogeneous nature of HS, we conclude that the automated procedure provides purified HS fractions that are comparable with those obtained with the manual procedure. In addition, the results in Table 3 show that the general properties of HA and FA are consistent among the different source materials (soil, waste, aquatic).

\section{Conclusions}

The presented automated system greatly facilitates isolation and characterization of HS. The system significantly reduces the total throughput time needed, from 6-7 days to $48 \mathrm{~h}$, and the amount of labor required to obtain purified HS for further characterization. The properties of purified
HS obtained with the automated procedure are comparable with published values for HS from a variety of sources, including standard HS from the IHSS. Our results also show that the general properties of HA and FA are consistent among the different source materials (soil, waste, aquatic) used in this study. Automation of the isolation and purification procedure reduces the risk of alterations in HS properties resulting from potentially prolonged standing of HS in acid and/or base, or effects from resin bleeding. Therefore, it is concluded that the presented automated procedure enables better standardization of HS isolation and purification methods because of the standard operating protocol facilitated by the software.

Acknowledgment D. Hoede, F. Kuijper, R. de Moel, R. van Rossum, and T. Schrijver are thanked for their significant technical contributions and J.P. Pinheiro for critically reading earlier versions of the manuscript. This work was partly funded by the Ministry of Spatial Planning, Housing and the Environment as part of ECN's environmental research program.

\section{References}

1. Hayes MHB, Swift RS (1990) Genesis, isolation, composition and structures of soil humic substances. In: de Boodt MF (ed) Soil colloids and their associations in aggregates. Plenum Press, New York

2. Swift RS (1996) Organic matter characterization. In: Sparks DL (ed) Methods of soil analysis, Part 3, Chemical methods. Soil Science Society of America, Madison, WI

3. Aiken GR (1985) Isolation and concentration techniques for aquatic humic substances. In: Aiken GR, McKnight DM, Wershaw RL, MacCarthy P (eds) Humic substances in soil, sediment and water: geochemistry, isolation and characterization. Wiley-Interscience, New York

4. Thurman EM, Malcolm RL (1981) Environ Sci Technol 15:463466

5. Leenheer JA (1981) Environ Sci Technol 15:578-587

6. van Zomeren A, Comans RNJ (2007) Environ Sci Technol 41:6755-6761

7. Stevenson FJ (1982) Humus chemistry. Genesis, composition, reactions. Wiley, New York

8. Malcolm RL (1991) Factors to be considered in the isolation and characterization of aquatic humic substances. In: Boren H, Allard B (eds) Humic substances in the aquatic and terrestrial environment. Wiley, London

9. Aiken GR (1988) A critical evaluation of the use of macroporous resins for the isolation of aquatic humic substances. In: Frimmel FH Christman RF (ed) Humic substances and their role in the environment. Wiley, New York

10. Chin YP, Aiken GR, O’Loughlin E (1994) Environ Sci Technol 28:1853-1858

11. Ma H, Allen HE, Yin Y (2001) Water Res 35:985-996

12. Steelink C (1985) Implications of elemental characteristics of humic substances. In: Aiken GR, McKnight DM, Wershaw RL, MacCarthy P (eds) Humic substances in soil, sediment, and water; geochemistry, isolation, and characterization. Wiley, New York 